\title{
Surgery of postinfarction ventricular septal rupture: The effect of David infarct exclusion versus Daggett direct septal closure on early and late outcomes
}

\author{
Runar Lundblad, MD, PhD, ${ }^{\mathrm{a}}$ and Michel Abdelnoor, $\mathrm{MPH}, \mathrm{PhD}^{\mathrm{b}, \mathrm{c}}$
}

\begin{abstract}
Objective: David infarct exclusion and Daggett direct septal closure are alternative techniques to repair postinfarction ventricular septal rupture. The aim of the present study was to compare the 2 methods with regard to postoperative morbidity, 30-day mortality, and long-term survival.
\end{abstract}

\begin{abstract}
Methods: From May 1981 to December 2010, 110 patients underwent surgery for postinfarction ventricular septal rupture. Data were collected on the clinical, angiographic, and echocardiographic findings, operative procedures, early morbidity, and survival time. The epidemiologic design was of an exposed (David infarct exclusion, $n=42$ ) versus a nonexposed (Daggett direct closure, $n=68$ ) cohort with 3 endpoints: postoperative morbidity, 30-day mortality, and long-term survival. The crude effect of the repair technique versus the endpoint was estimated using univariate statistics. Stratification analysis using the Mantel-Haenszel method was done to quantify the confounders and pinpoint the effect modifiers. Adjustment for confounders was performed using logistic regression and Cox regression analysis, and with propensity score stratification statistics. Survival curves were analyzed using the Breslow test and log-rank test.
\end{abstract}

Results: The surgical technique had no influence on postoperative morbidity. The 30 -day mortality was $16.7 \%$ in the David group and $48.5 \%$ in the Daggett group $(P=.000)$. Long-term survival was greater after David than after Daggett, with 5- and 10-year survival of $69 \%$ versus $38 \%$ and $48 \%$ versus $27 \%$, respectively $(P=.004)$. Total coronary revascularization improved survival more in the David than in the Daggett group.

Conclusions: David infarct exclusion was superior to Daggett direct septal closure for early and late survival after surgery for postinfarction ventricular septal rupture. Total coronary revascularization improved survival more in the David than in the Daggett group. (J Thorac Cardiovasc Surg 2014;148:2736-42)

Ventricular septal rupture (VSR) is a fatal complication after acute myocardial infarction (MI) and represents a major surgical challenge. Thrombolytic therapy and acute percutaneous coronary intervention have led to a significant reduction in myocardial necrosis and to a 5- to 10-fold reduction in the occurrence of postinfarction $\mathrm{VSR}^{1-4}$; however, the operative risk remains high. Surgical repair of VSR was first reported in 1957 by Denton A. Cooley, ${ }^{5}$ using a polyvinyl sponge to plug a posterior VSR. Subsequently, surgeons adapted techniques from congenital cardiac surgery, in which the septum was approached from the right side of the heart. However, on the right side, the apical septum is more trabeculated and the overview is poor, making VSR repair more difficult. Another disadvantage

From the Department of Thoracic and Cardiovascular Surgery, ${ }^{\text {a }}$ Oslo University Hospital, Rikshospitalet, Oslo, Norway; Centre for Biostatistics and Epidemiology, ${ }^{\mathrm{b}}$ Oslo University Hospital, Ullevål, Oslo, Norway; and University of Oslo, ${ }^{\mathrm{c}}$ Oslo, Norway.

Disclosures: Authors have nothing to disclose with regard to commercial support. Received for publication March 23, 2014; revisions received May 26, 2014; accepted for publication June 13, 2014; available ahead of print Aug 16, 2014.

Address for reprints: Runar Lundblad, MD, PhD, Department of Thoracic and

Cardiovascular Surgery, Oslo University Hospital, Rikshospitalet, Postbox 4950,

Nydalen, Oslo N-0424, Norway (E-mail: runar.lundblad@gmail.com).

$0022-5223 / \$ 36.00$

Copyright (c) 2014 by The American Association for Thoracic Surgery

http://dx.doi.org/10.1016/j.jtcvs.2014.06.076 of right ventriculotomy is that healthy myocardium is sacrificed. Subsequently, the technique of Willard M. Daggett, $\mathrm{Jr}^{6}$ with infarctectomy and direct closure of the VSR from the left side, with or without a patch, became the standard procedure, until Tirone David and colleagues ${ }^{7}$ in 1987 introduced the infarct exclusion technique without infarctectomy. The David method has gained worldwide popularity; however, few studies have compared the David and Daggett repair on early and late outcomes.

\section{METHODS}

The institutional review board and the regional ethics committee approved the study.

\section{Patients}

During a 30-year period, from May 1981 to December 2010, 114 consecutive patients from the south of Norway were referred to our hospital with postinfarction VSR. Four patients died before reaching surgery; thus, 110 underwent VSR repair and were included in the present study for followup. David infarct exclusion repair was performed in 42 patients and traditional Daggett direct VSR closure in 68. The preoperative cardiologic assessment was performed at our institution and included 2-dimensional Doppler echocardiography and selective coronary angiography for all patients. Details of coronary revascularization were collected from the operative records and correlated with the angiographic findings. Each patient was categorized into a "yes" or "no" group for culprit revascularization (infarct-related artery) and total revascularization (infarct-related 


\section{Abbreviations and Acronyms \\ $\mathrm{CABG}=$ coronary artery bypass grafting \\ MI = myocardial infarction \\ PS = propensity score \\ VSR $=$ ventricular septal rupture}

artery plus remote arteries). The preoperative and operative characteristics are summarized in Table 1. Altogether, 80 patients were men and 30 were women, with median age of 67 years (range, 43-85). Of the 110 patients, 97 had not experienced MI previously, and 13 had a history of 1 previous MI. Thrombolysis was performed in 19 cases and acute percutaneous coronary intervention in 9 , and reperfusion therapy was more common in the more recent David era $(P=.004)$. The interval from MI to the diagnosis of VSR was a median of 5 days (range, 1-27) and did not change throughout the study period. The interval from VSR to surgery was a median of 1 day (range, 0.5-60) and decreased from 3 days in the first half to 1 day in the second half of the study period $(P=.07)$. Daggett repair dominated in the first half of the study period and David repair in the second half. Accordingly, a tendency was seen toward a shorter interval from VSR to surgery in the David group (1 day) than in the Daggett group ( 2 days; $P=.24$ ). Shock at surgery was present in 21 patients and was strictly defined as hypoperfusion, leading to acute oliguria/anuria or an acute increase in creatinine to $>200$ $\mu \mathrm{mol} / \mathrm{L}$ or the need of preoperative dialysis. None of the patients experienced preoperative chronic renal failure that could confound this definition. All patients had significant coronary lesions, and, for the whole cohort, the number of paitents with 1-, 2-, and 3-vessel disease was 41, 31, and 38 , respectively. The left anterior descending artery was the infarctrelated artery in all cases with anterior VSR. The right coronary artery or its ramus descending posterior was the infarct-related artery in all cases with posterior VSR, except in 1 patient with occlusion of a dominant circumflex artery and 1 patient with a large left anterior descending artery coursing around the apex and supplying the posterior septum. Total coronary revascularization was more frequent $(P=.00)$ and the number of distal anastomoses was borderline greater $(P=.09)$ in the David group.

\section{Surgical Procedure}

The operation was performed through a median sternotomy using cardiopulmonary bypass and moderate systemic hypothermia. Antegrade St Thomas crystalloid solution was infused for cardioplegic arrest in all cases except 2 , for which the repair was performed on the beating heart. The VSR was approached through the infarction area of the left ventricle and was repaired using the David infarct exclusion repair or the traditional Daggett direct septal closure technique. In David repair, the infarcted septum and free wall myocardium was excluded using a large patch of bovine pericardium. In a few cases, it was supplemented with a smaller second patch directly on the VSR itself. The ventriculotomy was closed without infarctectomy, using buttressed sutures. In the Daggett repair, the VSR was patched in all cases except for 1, in which the defect was closed directly with buttressed interrupted sutures. Infarctectomy was eventually performed, and the ventriculotomy was closed using buttressed sutures. In a few cases, resected infarcted myocardium was replaced with prosthetic material. Glue was not used in any patient. Two patients had mitral annuloplasty, one had tricuspid annuloplasty, and one had mitral plus tricuspid annuloplasty. Coronary artery bypass grafting $(\mathrm{CABG})$ was performed whenever significant coronary artery disease was present and the vessel periphery was deemed suitable for revascularization. The left internal mammary artery and a saphenous vein were used for the grafts. Distal anastomoses were performed on a cardioplegic heart. Finally, proximal anastomoses were performed on a beating heart. Altogether, 29 patients underwent revascularization of the culprit artery and 27 underwent total coronary revascularization (culprit artery plus remote arteries). Coronary revascularization was more extensive in the David group, although the extent of coronary artery disease did not differ between the 2 groups (Table 1). The David procedure involves suturing of a larger patch; thus, the aortic crossclamp time was longer. An intra-aortic balloon pump was used in 99 patients as a part of the treatment strategy, and the duration was a median of 4 days (range, $0-15$ ) postoperatively. The intra-aortic balloon pump was not used in 11 patients, either because it was judged unnecessary owing to hemodynamic stability or it was impossible to introduce the balloon into a femoral artery.

\section{Study Design, Data Collection, and Statistical Analysis}

The study was a single-center observational cohort analysis of 110 consecutive patients who underwent surgery for postinfarction VSR in our hospital during a 30-year period, from May 1981 to December 2010. This dynamic cohort had a different entry time (date of operation), and the common closing date was March 1, 2014. Data were collected from the patient records, and the survival data were entirely determined from the information from the Norwegian National Population Registry. The follow-up data were $100 \%$ complete, and the follow-up duration was a mean of $6.1 \pm 6.8$ years. Survival after VSR repair and the reported outcomes after David and Daggett repairs have differed widely in published studies, making the sample size calculation uncertain. A conservative a priori power analysis showed that altogether 90 to 110 patients were needed to detect a death rate ratio of 0.5 between the David and Daggett groups, with $80 \%$ power and a type I error of $<5 \%$.

The epidemiologic design was of an exposed (David repair, $n=42$ ) versus nonexposed (Daggett repair, $\mathrm{n}=68$ ) cohort with 3 endpoints: postoperative morbidity, 30-day mortality, and long-term survival. First, we estimated the crude effect of the repair technique versus the endpoints using univariate statistics. Next, stratification analysis using the Mantel-Haenszel method was performed to quantify the confounders and pinpoint the effect modifiers according to the Breslow-Day test for the heterogeneity of the hazard ratios between strata. ${ }^{8,9}$ The confounding effect was quantified comparing the adjusted Mantel-Haenszel odds ratios or rate ratios with the corresponding crude values:

$$
\text { Confounding effect }(\%)=\frac{\mathrm{OR}_{\mathrm{MH}}-\mathrm{OR}_{\mathrm{CRUDE}}}{\mathrm{OR}_{\mathrm{CRUDE}}} \times 100
$$

The following variables were screened: age, sex, diabetes mellitus, body mass index, lung disease, previous MI, left ventricular ejection fraction, number of coronary vessels diseased, left main disease, anterior or posterior VSR, interval from MI to the diagnosis of VSR in days, interval from the diagnosis of VSR to surgery in days, the presence of shock at surgery, culprit revascularization, total revascularization, surgical experience (number of procedures per surgeon), and period of operation (first or second half of the study period). The David procedure involves suturing of a larger patch; thus, the aortic crossclamp time and cardiopulmonary bypass times were longer. Accordingly, these 2 variables were surrogates for the repair technique itself and were not adjusted for in the multivariable analysis.

Logistic regression and Cox regression analyses were performed to adjust for confounders with a $>5 \%$ numeric confounding effect. ${ }^{8}$ Manual, backward elimination of variables was performed, according to the following criteria: clinical or pathophysiologic importance, correlation matrix among the variables, and statistical significance of the Wald test. Finally, we used the propensity score (PS) method, which creates a quasirandomized situation. ${ }^{10}$ The PS can be helpful in as an adjunct to conventional stratification and regression methods to adjust for selection bias in observational studies. ${ }^{11}$ The PS is the conditional probability for a patient to undergo the David repair method given the individual covariates. Because we were on the border of power for valid statistical comparison between the 2 treatment groups, we used Mantel-Haenszel stratification on quintiles of the PS. The PS stratification method has, in contrast to the PS matching technique, the advantage of potentially using all the patients for analysis. The individual scores were ordered and divided into 5 groups of equal size, such that the patients in each quintile all had a close probability of 
TABLE 1. Patient data

\begin{tabular}{|c|c|c|c|}
\hline Variable & $\begin{array}{c}\text { David } \\
(n=42)\end{array}$ & $\begin{array}{l}\text { Daggett } \\
(n=68)\end{array}$ & $\begin{array}{c}P \\
\text { value* }\end{array}$ \\
\hline Age (y) & $71(47-85)$ & $67(43-81)$ & .09 \\
\hline Male sex & 29 & 51 & .50 \\
\hline Diabetes mellitus & 7 & 6 & .24 \\
\hline Lung disease & 8 & 8 & .29 \\
\hline $\mathrm{BMI}\left(\mathrm{kg} / \mathrm{m}^{2}\right)$ & $25.5 \pm 2.8$ & $24.4 \pm 2.8$ & .08 \\
\hline Previous MI & 2 & 11 & .13 \\
\hline 1-, 2-, 3-Vessel disease & $16,9,17$ & $25,22,21$ & .41 \\
\hline Left main stenosis & 2 & 7 & .30 \\
\hline VSR & & & .32 \\
\hline Anterior & 22 & 29 & \\
\hline Posterior & 20 & 39 & \\
\hline $\operatorname{ASAT}_{\max }(\mathrm{U} / \mathrm{L}) \dagger$ & $647 \pm 710$ & $468 \pm 324$ & .73 \\
\hline Thrombolysis or acute PCI & 17 & 11 & .00 \\
\hline MI to VSR interval (d) & $5(1-14)$ & $6(1-27)$ & .50 \\
\hline VSR to surgery interval (d) & $1(0.5-30)$ & $2(0.5-60)$ & .24 \\
\hline Shock at surgery & 6 & 15 & .31 \\
\hline Era of operation & & & .00 \\
\hline First half (1981-1996) & 0 & 55 & \\
\hline Second half (1996-2010) & 42 & 13 & \\
\hline Use of IABP & 40 & 59 & .20 \\
\hline Aortic crossclamp time (min) & $84 \pm 32$ & $56 \pm 31$ & .00 \\
\hline CPB time (min) & $135 \pm 53$ & $111 \pm 47$ & .01 \\
\hline Reperfusion time (min) & $51 \pm 26$ & $56 \pm 30$ & .49 \\
\hline Culprit revascularization $\ddagger$ & 24 & 5 & .00 \\
\hline Total revascularization & 23 & 4 & .00 \\
\hline Distal anastomoses (n) & $2(1-5)$ & $1(1-3)$ & .09 \\
\hline
\end{tabular}

Data presented as mean \pm standard deviation, median (range), or $n$. BMI, Body mass index; $M I$, myocardial infarction; VSR, ventricular septal rupture; $A S A T_{\max }$, maximum aspartate aminotransferase; $P C I$, percutaneous coronary intervention; $I A B P$, intra-aortic balloon pump; $C P B$, cardiopulmonary bypass. *Chi-square test or 2-tailed Fisher's exact test for discrete numeric data or categorical data and 2tailed $t$ test or Mann-Whitney $U$ test for continuous numeric data. $\nmid \mathrm{ASAT}_{\max }$ after MI measured in 46 patients (Daggett 31, David 15). †Revascularization of the infarct-related artery.

undergoing the David repair. By dividing the PS into quintiles, it was possible to produce strata with a balance between the treatment groups within each quintile and to remove $>90 \%$ of the bias due to each of the covariates. ${ }^{12}$ Because we used the prognostic strategy of PS estimation analysis, the predictive accuracy of the model was evaluated by calibration and discrimination. Calibration was evaluated using the HosmerLemeshow goodness of fit test. Discrimination was evaluated by the analysis of the area under the receiver operating characteristic curve. If the area under the curve is $>0.7$, it can be concluded that the model has acceptable discriminatory capability. We assessed the balance in baseline variables between the David and Daggett groups within the quintiles of the PS using the standardized difference method. We generated a PS using the logistic model and included the following variables: sex, age, presence of diabetes, hypertension, lung disease, previous MI, 3-vessel disease, complete revascularization, and preoperative shock. The Hosmer-Lemeshow test was not significant $(P=.30)$, indicating a useful goodness of fit for the model. The predictors of undergoing the David procedure using the constructed logistic model demonstrated good discriminatory power. The area under the receiver operating characteristic curve was 0.87 .

Continuous numeric data are presented as the mean \pm standard deviation or median and range and categorical data as numbers or fractions of patients. Univariable analysis was performed, using $2 \times 2$ tables and the chi-square test or 2-tailed Fisher's exact test for categorical data and the 2-tailed $t$ test or Mann-Whitney $U$ test for continuous numeric data. Survival curves were plotted according to the Kaplan-Meier method, and differences between curves were pinpointed using the Breslow test and log-rank test. ${ }^{13}$ SPSS for Windows, version 22 (IBM SPSS Statistics, Armonk, NY) and OpenEpi, version 2.3 (OpenEpi: Open Source Epidemiologic Statistics for Public Health, available at: http://www.OpenEpi.com), were used for the statistical calculations. The reporting of the results was performed in accordance with the Strengthening the Reporting of Observational Studies in Epidemiology guidelines for cohort studies. ${ }^{14,15}$

\section{RESULTS \\ Postoperative Morbidity}

Early outcome and postoperative morbidity are listed in Table 2. The VSR repair technique had no affect on early morbidity, except for a tendency toward a greater incidence of postoperative renal failure in the Daggett group $(P=.07)$. Reoperation for wound bleeding was performed in 15 patients, and 5 patients underwent reoperation for deep sternal infection. The most common postoperative organ malfunctions were renal and respiratory failure. Six patients (David 2, Daggett 4) with low cardiac output required perioperative mechanical circulatory assistance with centrifugal pumps. Of these 6 patients, 5 had posterior $\mathrm{VSR} ; 4$ required right ventricular assistance, and 1 required venoarterial cardiac bypass using extracorporeal membrane oxygenation. One patient with anterior VSR received left ventricular assistance. However, 4 of these 6 patients died early (intraoperatively or on day 8, 13, or 15), and 2 were late survivors (4 and 6 years). Examination for postoperative shunt was performed by echocardiography or oximetry in 88 patients (David 41, Daggett 47) within the first 30 days postoperatively. However, a shunt examination was not undertaken at a defined point. For those who underwent echocardiography, shunt quantification was not performed systematically. Of the 88 patients examined, 30 had residual or recurrent shunt (David 16, Daggett 14; $P=.26$ ), and 14 underwent reoperation (David 8, Daggett 6).

\section{Thirty-Day Mortality}

The 30-day mortality was $36.4 \%$ for all patients; $16.7 \%$ in the David group and $48.5 \%$ in the Daggett group $(P=.001$, univariable). Six confounders were identified (confounding effect in parentheses): body mass index $>25 \mathrm{~kg} / \mathrm{m}^{2}(18 \%)$, age $>70$ years $(-9 \%)$, lung disease $(-7 \%)$, left main stenosis $(-7 \%),>2$ days from VSR to surgery $(-7 \%)$, and previous MI $(6 \%)$. When adjusted for confounders in logistic regression analysis, the 30-day mortality was lower in the David group than in the Daggett group (odds ratio, 0.2; $P=.001$; Table 3). Stratification analysis, using the Mantel-Haenszel method on the quintiles of the PS, confirmed the beneficial effect of David repair on the early outcome, showing an adjusted odds ratio of 0.29 compared with the Daggett group (95\% confidence interval, $0.10-0.92 ; P=.027)$. The 30-day 
TABLE 2. Early outcomes

\begin{tabular}{lccr}
\hline \multicolumn{1}{c}{ Variable } & $\begin{array}{c}\text { David } \\
(\mathbf{n = 4 2})\end{array}$ & $\begin{array}{c}\text { Daggett } \\
(\mathbf{n = 6 8})\end{array}$ & $\begin{array}{c}\boldsymbol{P} \\
\text { value* }\end{array}$ \\
\hline Wound bleeding $(\mathrm{mL})$ & $1271 \pm 1377$ & $1081 \pm 1077$ & .36 \\
Reoperation for bleeding & 4 & 11 & .30 \\
Malign ventricular arrhythmia & 3 & 7 & .74 \\
Cerebral stroke & 1 & 8 & .15 \\
Tracheostomy & 9 & 13 & .79 \\
Renal failure $\dagger$ & 5 & 17 & .06 \\
Multiorgan failure & 7 & 18 & .22 \\
Deep sternal infection & 1 & 4 & .65 \\
Sepsis & 2 & 6 & .48 \\
Postoperative duration of & $4(0-15)$ & $4(0-12)$ & .49 \\
$\quad$ IABP (d) & & & \\
VAD or ECMO & 4 & 2 & .20 \\
Residual or recurrent shunt $\dagger$ & $16 / 41$ & $13 / 47$ & .33 \\
Death intraoperatively & 2 & 4 & 1.00 \\
30-d mortality & 7 & 33 & .00 \\
\hline Dapresc
\end{tabular}

Data presented as mean \pm standard deviation, median (range), or $\mathrm{n}$. IABP, Intra-aortic balloon pump; $V A D$, ventricular assist device; $E C M O$, extracorporeal membrane oxygenation. *Chi-square test or 2-tailed Fisher's exact test for categorical data and the Mann-Whitney $U$ test for continuous numeric data. $\dagger$ New postoperative renal failure defined as maximal postoperative creatinine $>200 \mu \mathrm{mol} / \mathrm{L}$ or the need for dialysis; patients with preoperative renal failure $(\mathrm{n}=21)$ or who died intraoperatively were excluded. $\ddagger$ Residual or new shunt within 30 days postoperatively; the examination for shunt within 30 days was performed in 88 patients (David 41, Daggett 47).

mortality decreased from $49.1 \%$ in the first half to $23.6 \%$ in the second half of the study period $(P=.006$, univariable). Six patients died intraoperatively ( 2 in the David group and 4 in the Daggett group; $P=.41$ ). The cause of death was low cardiac output in 23 , noncardiac organ failure or multiorgan failure in 10, cerebral stroke in 2, and unknown in 5 . No difference was seen between the 2 surgical groups in the cause of death. Total coronary revascularization reduced the 30-day mortality, on both univariable and logistic regression analysis. It was a strong effect modifier on the association between the repair method and 30-day mortality, because it improved the

TABLE 3. David versus Daggett repair: adjusted effect on mortality

\begin{tabular}{|c|c|c|c|c|c|c|}
\hline Variable & Level & B & $\begin{array}{c}\text { SE } \\
\text { of B }\end{array}$ & $\begin{array}{c}\text { OR } \\
\text { or RR }\end{array}$ & $\begin{array}{c}95 \% \mathrm{CI} \\
\text { of } \mathrm{OR} \\
\text { or RR } \\
\end{array}$ & $\begin{array}{c}P \\
\text { value } \\
\end{array}$ \\
\hline \multicolumn{7}{|l|}{ 30-d mortality } \\
\hline David repair & Yes vs no & -1.6 & 0.5 & 0.2 & $0.1-0.5$ & $.001 *$ \\
\hline Constant & & -0.1 & 0.2 & 0.9 & & $.81 *$ \\
\hline \multicolumn{7}{|l|}{ Total mortality } \\
\hline David repair & Yes vs no & -0.9 & 0.3 & 0.4 & $0.2-0.7$ & $.001 \dagger$ \\
\hline Age $>70 y$ & Yes vs no & 0.5 & 0.2 & 1.7 & $1.1-2.6$ & $.027 \dagger$ \\
\hline Coronary disease & $1-, 2-, 3-\mathrm{VD}_{\ddagger}^{\dagger}$ & 0.5 & 0.2 & 1.6 & $1.1-2.5$ & $.043 \dagger$ \\
\hline
\end{tabular}

David $(\mathrm{n}=42)$ versus Daggett $(\mathrm{n}=68)$ repair of postinfarction ventricular septal rupture. $\beta$, Regression coefficient; $S E$, standard error; $O R$, odds ratio (30-d mortality); $R R$, rate ratio (total mortality); $C I$, confidence interval; $V D$, vessel disease. *Logistic regression analysis with manual backward elimination. $\dagger$ Cox proportional hazards regression analysis with backward manual elimination. $\ddagger$ Number of coronary arteries diseased: 1, 2, or 3-vessel disease.
TABLE 4. Total coronary revascularization: effect modification on early and late survival

\begin{tabular}{|c|c|c|c|c|}
\hline Variable & $\begin{array}{c}\text { David } \\
(n=42) \\
\end{array}$ & $\begin{array}{l}\text { Daggett } \\
(n=68) \\
\end{array}$ & $\begin{array}{c}\text { OR } \\
\text { RRS }_{\text {SS }} \\
(\mathbf{9 5} \% \mathrm{CI}) \\
\end{array}$ & $\begin{array}{c}\text { Breslow- } \\
\text { Day* }\end{array}$ \\
\hline \multicolumn{5}{|l|}{$30-\mathrm{d}$ mortality $\dagger$} \\
\hline Total revascularization & & & & 0.05 \\
\hline Yes & $2 / 23$ & $3 / 4$ & $0.01(0.0-0.5)$ & \\
\hline No & $5 / 19$ & $30 / 64$ & $0.41(0.1-1.3)$ & \\
\hline \multicolumn{5}{|l|}{ Total mortality $\ddagger$} \\
\hline Total revascularization & & & & 0.02 \\
\hline Yes & $9 / 176$ & $4 / 12$ & $0.15(0.0-0.6)$ & \\
\hline No & $12 / 102$ & $62 / 378$ & $0.72(0.4-1.3)$ & \\
\hline
\end{tabular}

$O R_{S S}$, Stratum-specific odds ratio; $R R_{S S}$, stratum-specific rate ratio; $C I$, confidence interval. *Breslow-Day test for interaction over strata. $\dagger$ Data presented as numbers of 30-day deaths/numbers of patients at risk. ‡Data presented as numbers of deaths/numbers of patient-years of follow-up.

outcome more in the David group than in the Daggett group (interaction over strata; Table 4).

\section{Long-Term Survival}

The follow-up period was a mean of $6.1 \pm 6.8$ years (range, 0-27). The 5- and 10-year survival for all patients was $50 \%$ and $34 \%$, respectively. Long-term survival was greater after David repair than after Daggett repair, with 5- and 10-year survival of $69 \%$ versus $38 \%$ and $48 \%$ versus $27 \%$, respectively $(P=.04, \log$ rank; Figure 1$)$. Six confounders were identified (confounding effect in parentheses): age $>70$ years $(-26 \%)$, body mass index $>25 \mathrm{~kg} / \mathrm{m}^{2}(11 \%),>2$ days from VSR to surgery $(-8 \%)$, $>5$ days from MI to VSR $(-6 \%)$, 3-vessel disease $(-5 \%)$, and male sex $(6 \%)$. When adjusted for confounders in Cox regression analysis, long-term survival was greater after David repair than after Daggett repair (death rate

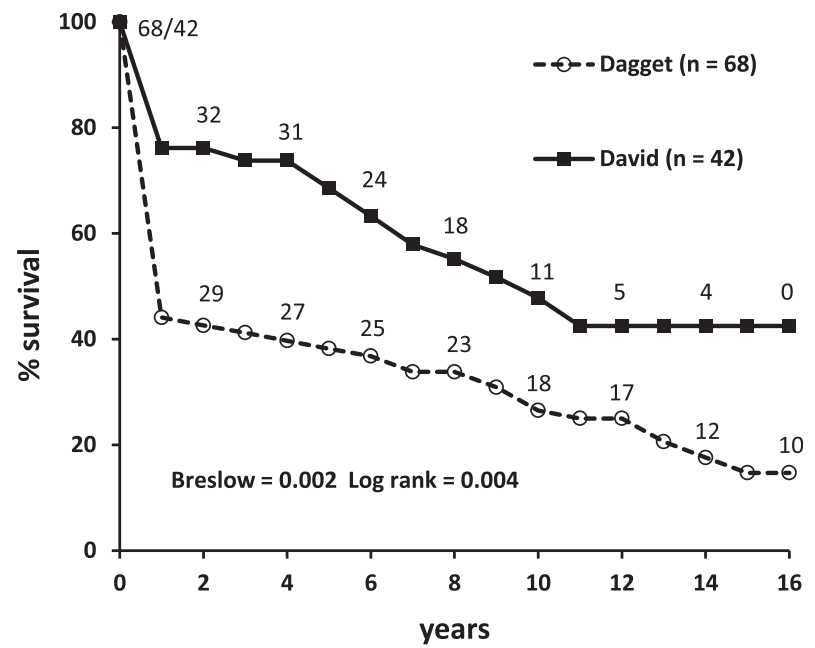

FIGURE 1. The effect of the ventricular septal repair technique (David vs Daggett) on long-term survival. Numbers on curves represent patients at risk. 
ratio $=0.4, P=.001$; Table 3 ). Stratification analysis, using the Mantel-Haenszel method on the quintiles of PS with the patient-year model, confirmed the beneficial effect of David repair on long-term survival, showing an adjusted death rate ratio of 0.46 compared with that for Daggett repair (95\% confidence interval, $0.26-0.84 ; P=.011)$. Total coronary revascularization improved long-term survival, on both univariable and Cox regression analysis. It was a strong effect modifier on the association between the repair method and long-term survival, because it improved the outcomes more in the David group than in the Daggett group (interaction over strata; Table 4).

\section{DISCUSSION}

The present study of surgery for postinfarction VSR has shown that David infarct exclusion repair is superior to Daggett direct septal closure technique for early and late survival. The surgical repair technique did not influence early morbidity. Since Tirone David introduced the Dor principle of a large endoventricular patch to exclude the VSR and infarcted myocardium, this operation has gained worldwide popularity. However, little evidence exists that the David repair is superior to the Daggett repair in the major endpoints. Owing to the low incidence and the acute and dramatic course of the disease, randomized studies are difficult to perform. A few retrospective studies have included both David and Daggett techniques ${ }^{16-20}$; however, the role of the repair method per se was not the focus. In a recent retrospective study, Kaneda and colleagues ${ }^{18}$ reported on 33 patients who underwent the Daggett $(n=14)$, David $(\mathrm{n}=5)$, or modified David $(\mathrm{n}=19)$ techniques, ${ }^{18}$ and the infarct exclusion techniques seemed superior on both early and late survival. However, they were retrospective cohort studies, using a prognostic strategy for observational reports. They only identify whether the repair method is a prognostic factor for survival but suggested no etiologic connection. In our study of 110 patients, we used a different approach: the etiologic strategy for observational studies. This epidemiologic design can more reliably pinpoint a cause-and-effect relationship, and it strengthens our finding that David infarct exclusion technique is superior for early and late survival.

The advantage of the Daggett procedure is that it is relatively easy to perform and the crossclamp time is shorter owing to the smaller patch and shorter suture line. The David technique includes several beneficial elements. First, infarct exclusion with a large patch moves the suture line away from the necrotic myocardium in the VSR area to more distant and healthy tissue. The tension on the sutures is reduced because of the long and running suture line and because the large patch rests on the left ventricular wall endocardium. Patch suturing can therefore be more secure in David repair, avoiding new shunt and cardiac failure in the vulnerable postoperative period. Second, infarct exclusion moves the left ventriculotomy to a low-pressure zone, with less risk of suture dehiscence and bleeding. We found no difference in the amount of postoperative mediastinal drainage or the frequency of reoperation for bleeding. However, the present study was strongly underpowered to detect any differences in the hazard of revision of bleeding. Third, David infarct exclusion usually results in no need for infarctectomy, making revascularization of the infarctrelated artery easier. This was supported by our finding that culprit revascularization was more frequent in the $\mathrm{Da}-$ vid group. Finally, preserving the infarcted myocardium might provide better geometry of the left ventricle, and infarct exclusion will prevent development of a left ventricular aneurysm.

The role of concomitant CABG during VSR repair has been controversial for several reasons. First, coronary angiography is time-consuming and potentially dangerous in an unstable patient. However, we have not lost any patient during angiography, and this is in accordance with the findings from several other studies. ${ }^{7,21-23}$ Second, the rationale for revascularization of the culprit artery and its infarcted myocardium can be argued. Third, the culprit artery is often close to the left ventriculotomy and can be damaged during infarctectomy or entrapped in the closure suture line. Finally, CABG increases the cardiopulmonary bypass and aortic crossclamp times, which is potentially harmful for a poor left ventricle. More than one half of the patients will have multivessel disease, and most surgeons will intuitively address this with concomitant $\mathrm{CABG}$ to remote coronary arteries. Most studies have shown no benefit from revascularization on early ${ }^{16,20,21,24-31}$ or late ${ }^{16,20,24,27,29,31}$ survival. Other studies have suggested that, independent of the VSR repair technique, coronary revascularization improves early ${ }^{17,23,32,33}$ and late $\mathrm{e}^{21,23,26,30,32,33}$ survival. None of these reports were of randomized trials; they were observational studies that analyzed whether CABG during VSR repair was a prognostic factor for survival. Accordingly, CABG could be a surrogate for several other factors, such as the extent of coronary disease, surgeon skill, and institutional routines. Our study showed that total coronary revascularization was a strong effect modifier on the association between repair method and outcome. Thus, total revascularization improved early and late survival more in the David group than in the Daggett group. We strongly believe that CABG controls the added risk of coronary artery disease and that it should be performed whenever it is technically possible.

\section{CONCLUSIONS}

The present study of surgery for postinfarction VSR has shown that David infarct exclusion repair is superior to Dagget direct septal closure technique for early and late survival. This was a large, single-center study that included all 
the patients referred with postinfarction VSR, without any exclusion criteria. The present study, therefore, reports the real world data and outcomes. However, the retrospective and observational design had some obvious limitations. First, the nonrandomized design could have led to a selection bias, residual confounding bias, and, eventually, some unknown confounders that were impossible to control for. Although we have tried to adjust for multiconfounder bias using stratification analysis, conventional regression methods, and propensity score statistics, hidden mechanisms of selection could have been present between the 2 surgical groups that we were unable to control for. Second, the quality of the pre-, peri-, and postoperative care has most probably improved during the study period of 30 years. Because the Daggett repair dominated in the early years and David in the more recent period, this could have favored the outcomes in the David group. Accordingly, we were not only comparing 2 surgical techniques, but also 2 different eras. Our results must therefore be interpreted with care. Third, our definition of shock at surgery differs from that of many other reports. We used a narrow and strict definition of shock: severe hypoperfusion leading to renal failure. We deliberately excluded parameters such as blood pressure, peripheral circulation, and mental consciousness. Shock is a dynamic process, and these parameters will vary from hour to hour, dependent on the treatment intervention and the natural disease course. Moreover, "soft" parameters are difficult to translate into variables that can be treated in statistical analysis. The use of an intra-aortic balloon pump and inotropic drugs cannot be used to define shock, because these interventions were performed in most of our patients as a part of a standard treatment regimen. Our definition of shock is valid and reliable, because acute renal failure in this setting reflects severe hypoperfusion, and the creatinine levels and urine output were consistently measured in all patients. Fourth, a learning curve effect of the surgical team could have been present throughout the study period. Altogether, 20 surgeons participated in the present study. Most of them received their training during the Daggett period and had become more experienced surgeons in the David period, which could represent a possible bias in favor of the David technique. Because few surgeons had gained significant experience, a benefit from surgical training could not be demonstrated in the statistical analysis.

\section{References}

1. Crenshaw BS, Granger CB, Birnbaum Y, Pieper KS, Morris DC, Kleiman NS, et al. Risk factors, angiographic patterns, and outcomes in patients with ventricular septal defect complicating acute myocardial infarction. Circulation. 2000;101:27-32.

2. Harikrishnan S, Tharakan J, Titus T, Kumar A, Sivasankaran S, Krishnamoorthy KM. Ventricular septal rupture following myocardial infarction: clinical, haemodynamic, angiographic profile and long-term outcome. Int J Cardiol. 2007;120:279-80.
3. Nakatani D, Sato H, Kinjo K, Mizuno H, Hishida E, Hirayama A, et al. Effect of successful late reperfusion by primary coronary angioplasty on mechanical complications of acute myocardial infarction. Am J Cardiol. 2003;92:785-8.

4. Yip HK, Fang CY, Tsai KT, Chang HW, Yeh KH, Fu M, et al. The potential impact of primary percutaneous coronary intervention on ventricular septal rupture complicating acute myocardial infarction. Chest. 2004;125:1622-8.

5. Cooley DA. Postinfarction ventricular septal rupture. Semin Thorac Cardiovasc Surg. 1998;10:100-4.

6. Daggett WM, Guyton RA, Mundth ED, Buckley MJ, McEnany MT, Gold HK et al. Surgery for post-myocardial infarct ventricular septal defect. Ann Surg. 1977; 186:260-71.

7. David TE, Dale L, Sun Z. Postinfarction ventricular septal rupture: repair by endocardial patch with infarct exclusion. J Thorac Cardiovasc Surg. 1995;110:1315-22.

8. Kleinbaum D, Kupper L, Muller K, Nizam A. Applied Regression Analysis and Other Multivariate Methods. 3rd ed. Pacific Grove, CA: Duxbury Press; 1998.

9. Kleinbaum D, Sullivan K, Barker N. ActivEpi Companion Textbook. New York: Springer-Verlag; 2003.

10. Rosenbaum PR, Rubin DB. The central role of the propensity score in observational studies for causal effects. Biometrika. 1983;70:41-55.

11. D'Agostino RB Jr. Propensity score methods for bias reduction in the comparison of a treatment to a non-randomized control group. Stat Med. 1998;17:2265-81.

12. Rosenbaum PR, Rubin DB. Reducing bias in observational studies using subclassification on the propensity score. J Am Stat Assoc. 1984;79:516-24.

13. Altman DG. Analysis of survival times. In: Practical Statistics for Medical Research. 1st ed. London: Chapman \& Hall; 1991:365-95.

14. Vandenbroucke JP, von Elm E, Altman DG, Gotzsche PC, Mulrow CD, Pocock SJ et al. Strengthening the Reporting of Observational Studies in Epidemiology (STROBE): explanation and elaboration. Epidemiology. 2007;18:805-35.

15. von Elm E, Altman DG, Egger M, Pocock SJ, Gotzsche PC, Vandenbroucke JP, et al. The Strengthening the Reporting of Observational Studies in Epidemiology (STROBE) statement: guidelines for reporting observational studies. Lancet 2007:370:1453-7.

16. Deja MA, Szostek J, Widenka K, Szafron B, Spyt TJ, Hickey MS, et al. Post infarction ventricular septal defect-can we do better? Eur J Cardiothorac Surg. 2000;18:194-201.

17. Fukushima S, Tesar PJ, Jalali H, Clarke AJ, Sharma H, Choudhary J, et al Determinants of in-hospital and long-term surgical outcomes after repair of postinfarction ventricular septal rupture. J Thorac Cardiovasc Surg. 2010;140:59-65.

18. Kaneda T, Saga T, Kitayama H, Nakamoto S, Satsu T, Nishino T, et al. Early and late results of surgical treatment for ventricular septal rupture with and without use of the infarction exclusion technique-experience with two- and threesheet modification. J Cardiac Surg. 2012;27:34-8.

19. Maltais S, Ibrahim RF, Basmadjian AJ, Carrier M, Bouchard D, Cartier R, et al Postinfarction ventricular septal defects: towards a new treatment algorithm? Ann Thorac Surg. 2009;87:687-93.

20. Mantovani V, Mariscalco G, Leva C, Blanzola C, Sala A. Surgical repair of postinfarction ventricular septal defect: 19 years of experience. Int J Cardiol. 2006; 108:202-6.

21. Cox FF, Plokker HW, Morshuis WJ, Kelder JC, Vermeulen FE. Importance of coronary revascularization for late survival after postinfarction ventricular septal rupture. A reason to perform coronary angiography prior to surgery. Eur Heart J. $1996 ; 17: 1841-5$

22. Deville C, Fontan F, Chevalier JM, Madonna F, Ebner A, Besse P. Surgery of post-infarction ventricular septal defect: risk factors for hospital death and long-term results. Eur J Cardiothorac Surg. 1991;5:167-75.

23. Pretre R, Ye Q, Grunenfelder J, Zund G, Turina MI. Role of myocardial revascularization in postinfarction ventricular septal rupture. Ann Thorac Surg. 2000;69:51-5.

24. Anderson DR, Adams S, Bhat A, Pepper JR. Post-infarction ventricular septal defect: the importance of site of infarction and cardiogenic shock on outcome. Eur J Cardiothorac Surg. 1989:3:554-7.

25. Arnaoutakis GJ, Zhao Y, George TJ, Sciortino CM, McCarthy PM, Conte JV. Surgical repair of ventricular septal defect after myocardial infarction: outcomes from the Society of Thoracic Surgeons National Database. Ann Thorac Surg. 2012;94:436-43.

26. Barker TA, Ramnarine IR, Woo EB, Grayson AD, Au J, Fabri BM, et al. Repair of post-infarct ventricular septal defect with or without coronary artery bypass grafting in the northwest of England: a 5-year multi-institutional experience. Eur J Cardiothorac Surg. 2003;24:940-6.

27. Dalrymple-Hay MJ, Langley SM, Sami SA, Haw M, Allen SM, Livesey SA, et al. Should coronary artery bypass grafting be performed at the same time as repair of a post-infarct ventricular septal defect? Eur J Cardiothorac Surg. 1998;13: 286-92. 
28. Jeppsson A, Liden H, Johnsson P, Hartford M, Rådegran K. Surgical repair of post infarction ventricular septal defects: a national experience. Eur J Cardiothorac Surg. 2005;27:216-21.

29. Labrousse L, Choukroun E, Chevalier JM, Madonna F, Robertie F, Merlico F, et al. Surgery for post infarction ventricular septal defect (VSD): risk factors for hospital death and long term results. Eur J Cardiothorac Surg. 2002;21:725-32.

30. Muehrcke DD, Daggett WM Jr, Buckley MJ, Akins CW, Hilgenberg AD, Austen WG. Postinfarct ventricular septal defect repair: effect of coronary artery bypass grafting. Ann Thorac Surg. 1992;54:876-82.
31. Pang PY, Sin YK, Lim CH, Tan TE, Lim SL, Chao VT, et al. Outcome and survival analysis of surgical repair of post-infarction ventricular septal rupture. J Cardiothorac Surg. 2013;8:44.

32. Lundblad R, Abdelnoor M, Geiran OR, Svennevig JL. Surgical repair of postinfarction ventricular septal rupture: risk factors of early and late death. J Thorac Cardiovasc Surg. 2009;137:862-8.

33. Perrotta S, Lentini S. In patients undergoing surgical repair of post-infarction ventricular septal defect, does concomitant revascularization improve prognosis? Interact Cardiovasc Thorac Surg. 2009;9:879-87. 